\title{
COMPARISON AND QUANTITATIVE STUDY OF VULNERABILITY/DAMAGE CURVES IN SOUTH AFRICA
}

\author{
T. PULE \\ Council for Geoscience, 280 Pretoria Road, Silverton, South Africa \\ e-mail: tpule@geoscience.org.za \\ C.J.S. FOURIE \\ Environmental Water and Earth Sciences, Tshwane University of Technology \\ e-mail: FourieCJS@tut.ac.za
}

\author{
A. KIJKO \\ University of Pretoria, Natural Hazard Centre, Africa \\ e-mail: andrzej.kijko@up.ac.za
}

\author{
V. MIDZI \\ Council for Geoscience, 280 Pretoria Road, Silverton, South Africa \\ e-mail: vmidzi@geoscience.org.za
}

(c) 2015 December Geological Society of South Africa

\begin{abstract}
Southern Africa is considered a stable continental region in spite of several reported medium size earthquakes, some of which caused considerable damage and casualties. The 1969 Ceres 6.3 magnitude earthquake is considered the most destructive and caused serious damage estimated at US\$24 million, with 12 mortalities and many more injured. Others include six mining related tremors which caused significant damage i.e. Welkom 1976, Klerksdorp 1977, Welkom 1989 and Carletonville 1992 seismic events. Notable for their damage to infrastructure was the 9th March 2005 Stilfontein event near Klerksdorp and 5th August 2014 event near Orkney.

Most buildings and structures in South Africa are not designed to resist even relatively low intensity earthquake. Most architects, engineers and builders in South Africa do not consider seismic resistance as a design requirement. In this work, potential damage caused by strong earthquake was estimated for three classes of buildings situated in Sandton, Cape Town, Durban and Port Elizabeth. The effect of earthquakes causing damage was studied by considering the "worst case-scenario", i.e. the occurrence of an earthquake with the maximum possible magnitude for an area. In four studied urban areas, expected damage was estimated for three classes of buildings: unreinforced masonry, bearing wall, low rise, reinforced concrete shear wall, without moment resisting frame, medium rise, and reinforced concrete shear wall, without moment resisting frame, high rise. The results of the analysis showed that in case of occurrence of a strong earthquake, the most damage is expected for the building classified as 'unreinforced masonry, bearing wall, low rise, and reinforced concrete shear wall'.
\end{abstract}

\section{Introduction}

Numerous studies have been conducted to estimate the risk of damage to buildings in urban areas of South Africa, due to seismic activity (Kijko et al., 2002; 2003; Davies and Kijko, 2003; Fernandez, 1974). The studies by Kijko et al. (2002; 2003) provided the seismic hazard and risk for Tulbagh in the Western Cape Province, where the strongest and most damaging tectonic earthquake of magnitude 6.3 in South Africa occurred. Davies and Kijko (2003) discussed the possible impact of seismic activity on the South African insurance industry by estimating seismic damage to buildings using a probabilistic (statistical) approach.

Although earthquakes of tectonic origin that are destructive are infrequent in South Africa, they have the potential to affect the insurance industry and the country as a whole. The occurrence of the destructive Ceres earthquake should be regarded as a warning of such potential (Theron, 1974). The event occurred on
29 September, 1969 in the Ceres-Tulbagh region of the Western Cape Province about $100 \mathrm{~km}$ northeast of Cape Town. Serious damage occurred to buildings in the area (valued at a total of U.S. \$24 million) (Singh et al., 2009). The structural damage to buildings varied from almost total destruction of old and poorly constructed buildings to large cracks in better designed and built structures (Figure 1). Twelve people were killed and many more injured (Singh et al., 2009). Other large events of tectonic origin felt in South Africa include the 1912 Koffiefontein earthquake of magnitude 6.2, the 31 December 1932 Cape St Lucia earthquake of local magnitude 6. Paleoseismic studies show that a large earthquake with an estimated magnitude of about 8 occurred in the area of Koffiefontein some 50,000 years ago (Visser and Joubert 1990; Joubert et al., 1991).

Moreover, there is a relatively high risk to structures in Gauteng due to mining related seismicity (Figure 2). A moderate to large earthquake could cause serious 

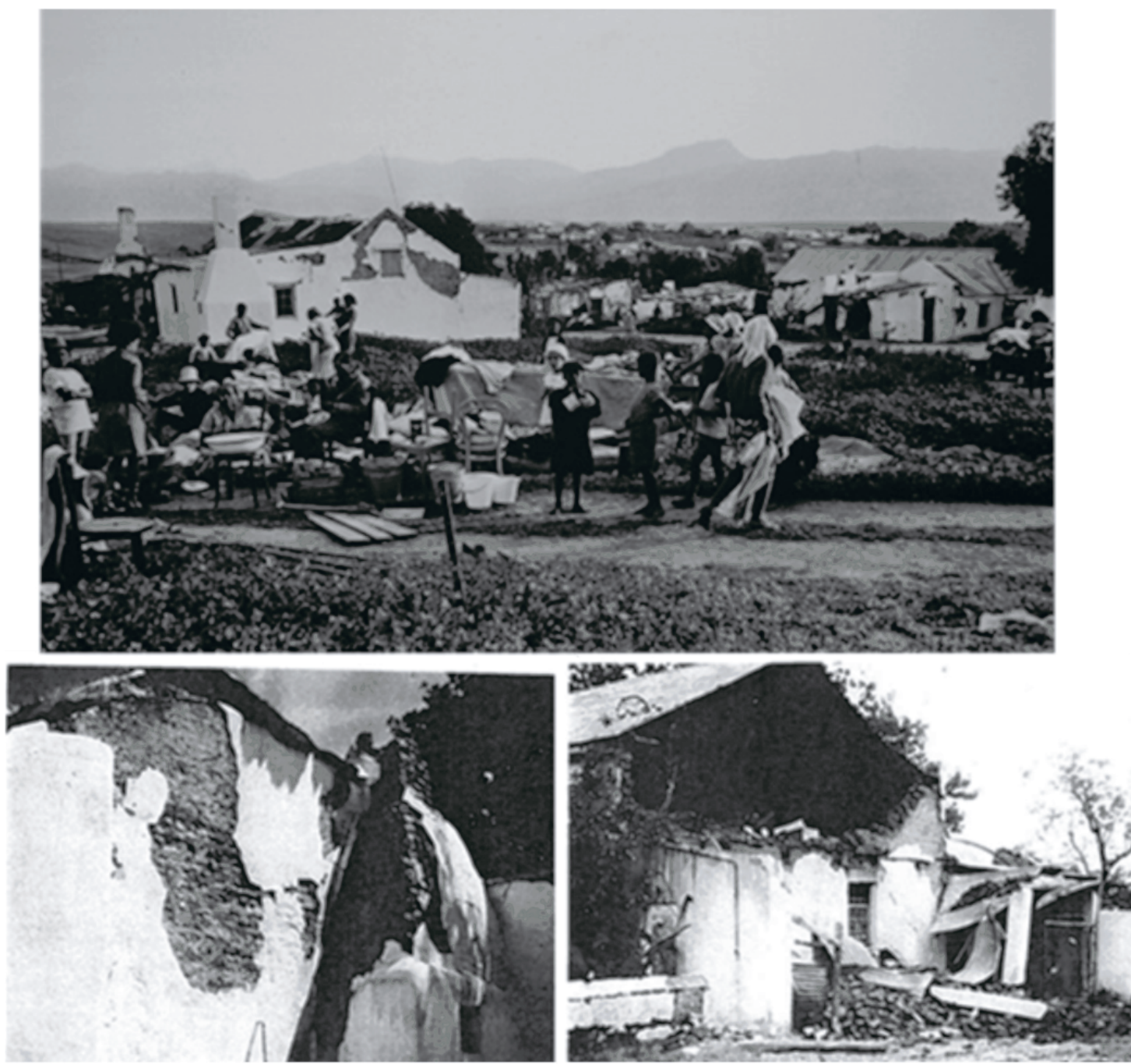

Figure 1. Damage observed at Tulbagh after the Ceres earthquake (adapted from Fernandez, 1974).

damage to structures in nearby cities and thus loss of life. The largest recorded earthquake in a mining area is the recent Orkney earthquake, which occurred on 5 August 2014 and had a local magnitude ca. 5.5 (Midzi et al., 2015). Other events include the 5 March 2005, Stilfontein earthquake (Durrheim et al., 2007), Welkom 1976, Klerksdorp 1977, Welkom 1989 and Carletonville 1992 events. Many of these events resulted in some level of damage to structures / buildings on the surface.

The foremost objective here is to define, prioritise and convince the South African building authorities to implement localised strategic steps to improve safety practices. As a best practise, a standardised tool should be developed to quantify this objective that uses a uniform engineeringbased loss estimation approach to quantify damage, economic loss and casualties throughout the country.
The metropolitan areas of Gauteng and Northwest Province, Cape Town, Durban, Port Elizabeth and Pietermaritzburg are in particular at a higher risk due to the increased number of residential, industrial and commercial structures. It has been proven that adherence to set minimum standards can significantly reduce the loss of life and damage as a result of large earthquakes (FEMA, 1994).

In a survey carried out by Pule and Singh (2010), only $19 \%$ of respondents from the South African engineering community considered earthquake effects in their structural designs/constructions. Given the damage observed historically, it is necessary to increase the awareness of the seismic risk under construction engineers by including seismic design parameters in their designs of structures. 
The practice of relating ground motion parameters to damage and losses by means of a damage probability matrix (DPM) was developed by Whitman et al. (1973). Thereafter, Whitman's earthquake loss-estimation formalism became standard and was applied around the world (e.g. in China, Chen et al., 1997; Yong et al., 1998; In the USA, Rojahn et al., 1997; Reitherman, 1985; Whitman, 1986; In New Zealand, Dowrick and Rhoades, 1990; 1993; In Russia, Shojgu et al., 1992; Italy, Bramerini et al., 1995; Orsini, 1999; Portugal, D’Ayala et al., 1997 and Germany, Tyagunov et al., 2006).

In general, the estimation of future expected damage to structures can be done in two different ways, by probabilistic and deterministic methods (Kijko, 2011). In this study, the deterministic method was used, with MM intensity levels used as a measure of ground motion. The main seismic parameters needed in deterministic seismic risk analysis for a selected site are, the area specific maximum possible earthquake magnitude $m_{\max }$ and ground motion prediction equation (GMPE). In the following section will discuss the procedure applied for calculation of $m_{\max }$ and the relevant GMPE for South Africa.

\section{Deterministic seismic risk analysis}

Deterministic seismic risk analysis (DSRA) involves the development of a particular seismic scenario, according to which expected damages/losses are calculated. The scenario consists of the assumed occurrence of a seismic event of a specified size and location. A typical DSRA procedure consists of the following five phases (Kijko, 2011):

- Identification and characterization of all seismic event sources capable of producing significant ground motion at the site.

- Selection of a particular "scenario seismic event", i.e., the event that is expected to produce the strongest level of shaking. The scenario seismic event is described in terms of its size and the distance from the site.

- Selection of a shortest source-to-site distance (scenario seismic event source to site). The distance may be expressed as an epicentral or hypocentral distance, depending on the type of distance, specified in the ground motion prediction equation (GMPE). Modified Mercalli (MM) intensity is preferred above peak ground acceleration (PGA) since: (i) in South Africa the area-characteristic ground motion prediction equations are known compared to the virtually non-existing peak ground acceleration (PGA) records, and

(ii) the vulnerability curves used in this report are provided in terms of MM intensity.

- Using the appropriate attenuation relation, a ground motion parameter is then computed for all respective sites. In this study an intensity attenuation equation was used and thus the ground motion is estimated in terms of intensity levels.

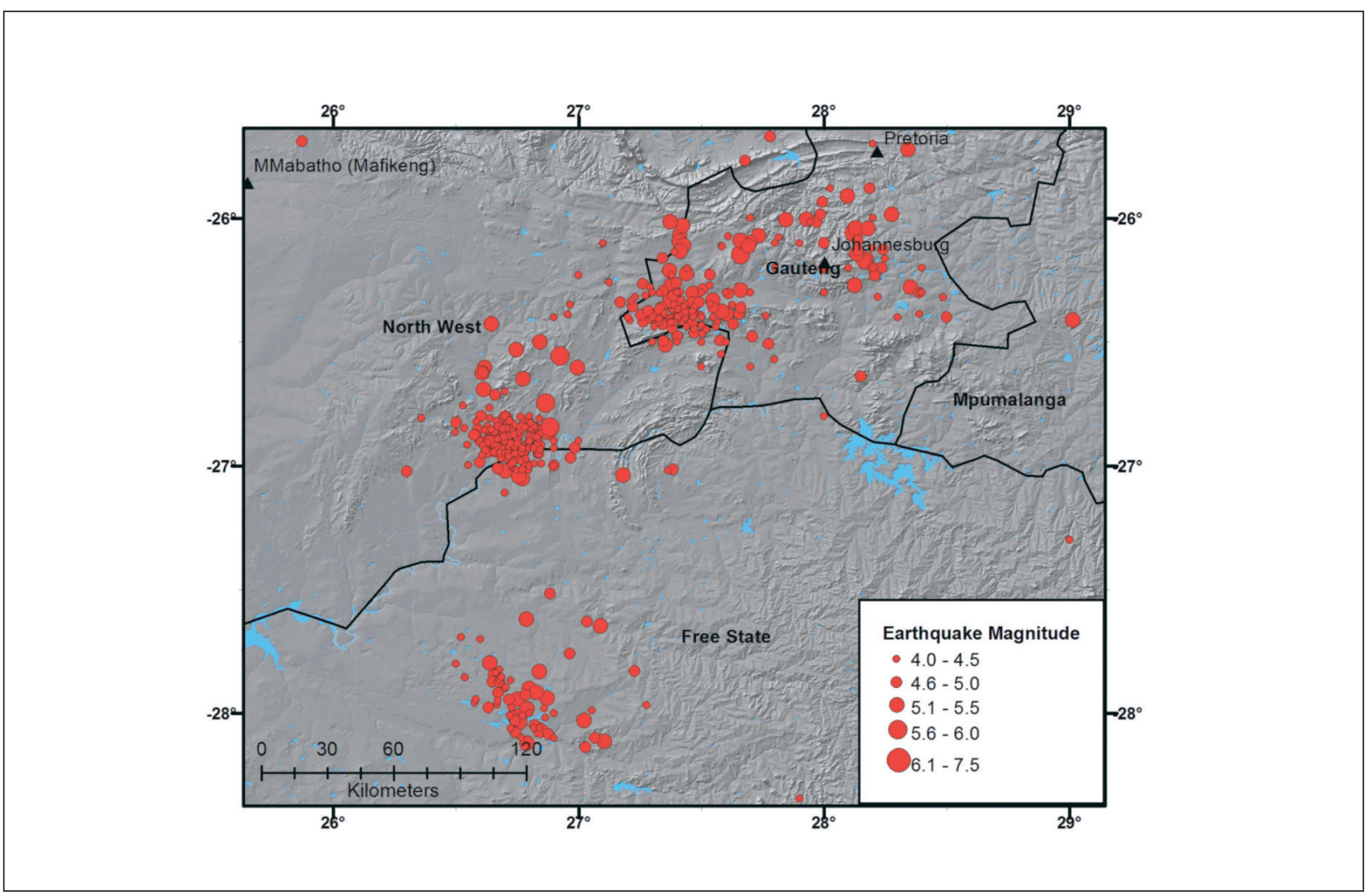

Figure 2. Mining related seismicity of magnitude 4.0 and above in the gold mining regions of South Africa. 
- Calculation of the expected damages/losses at the site that result from these ground motions. The deterministic estimates are based on a random set of "scenario seismic events" but they make use of statistical tools in providing a distribution for the expected damage (Davies and Kijko, 2003).

The extent of damage, ranging from none to total, is divided into damage states, each of which is described both by words and by a range of damage factors. The damage factor denotes the ratio of the value of the physical damage (due to the seismic event) to the replacement value (ATC-13, 1985). For each level of MM intensity of ground shaking, the numbers in the corresponding column of a Damage Probability Matrix (DPM, Whitman et al., 1973) provides the distribution of the expected damages. Note that the values in each column of the DPM sum to $100 \%$ because each number in the matrix is the probability that a building will experience a particular level of damage as the result of a particular intensity. The originality of the scale is that it imports the measurable calibration of damage, in terms of structural damage index, which depends on severity and the extent of damage. Damage probability matrices for the 12 building classes discussed in this study were adapted from ATC-13 (1985).

After the description of the damage states, a vulnerability curve is determined for each building class. The curve is calculated for each building class and presents the calculated average level of damage per level of intensity. The curve is represented by the following function:

$$
E[\mathrm{D} \mid i]=\int_{0}^{d_{\max }} d f_{D}(d \mid i) \mathrm{d} d,
$$

(equation 1)

where $E$ denotes the operator of expectancy and the function $E[\mathrm{D} \mid i]$ denotes the mean damage factor for a given MM intensity $i$ (ATC-13, 1985). When the function $E[\mathrm{D} \mid i]$ is plotted against ground shaking $i$, the plot is called a vulnerability curve. In this study the vulnerability curve provided by ATC-13 (1985) is used, in which the conditional probability density functions of damage, $f_{D}(d \mid i)$ are given in the form of Whitman's damage probability matrices $\mathrm{DPM}_{\mathrm{ij}}$ for seven damage states $j(j=1, \ldots, 7)$ and nine MM intensity levels $i$ ( $i=\mathrm{IV}, \ldots$, XII). In ATC-13 (1985), the damage states are called the central factors $C D F_{j}$ and are defined as:

- no damage when $C D F_{1}=0 \%$;

- slight damage when $C D F_{2}=0.5 \%$;

- light damage when $C D F_{3}=5 \%$;

- moderate damage when $C D F_{4}=20 \%$;

- heavy damage when $C D F_{5}=45 \%$;

- major damage when $C D F_{6}=80 \%$ and,

- total destruction when $C D F_{7}=100 \%$.

\section{Intensity attenuation relations}

An MM intensity attenuation relation, known also as the ground motion prediction equation (GMPE), is a relationship that translates the seismic event magnitude and the distance between the seismic event epicenter and the site of interest into the MM intensity at the site (Peruzza, 1996). The most commonly used MM intensity attenuation relation has the form:

$$
I_{0}-I=-a_{1}-a_{2} \mid \mathrm{n}(r)-a_{3} r, \quad(\text { equation } 2)
$$

where $a_{1}$ to $a_{3}$ are coefficients, $r$ is the epicentral or hypocentral distance in $\mathrm{km}, I$ is the MM intensity at the site and $I_{O}$ is the maximum (focal) MM intensity at the epicentre of the seismic event. The numerical values of the coefficients $a_{1}$ to $a_{3}$ are different for different regions and are usually estimated from MM intensity distribution maps of the region. Most often, the coefficients are calculated using linear regression (Carnahan et al., 1969). The MM intensity attenuation relations previously developed for the four regions of interest in this study by Kijko et al. (2006) are as follows:

Johannesburg :

$$
\left.I_{0}-I=-1.652+0.508 \ln (r)+0.0051 r \quad \text { (equation } 3\right)
$$

Durban :

$$
I_{0}-I=-0.959+0.325 \ln (r)+0.0075 r \quad(\text { equation } 4)
$$

Port Elizabeth :

$$
I_{0}-I=-2.982+1.203 \ln (r)+0.0010 r \quad \text { (equation 5) }
$$

Cape Town :

$$
I_{0}-I=-2.983+1.203 \ln (r)+0.0010 r \quad \text { (equation 6) }
$$

The empirical relation between seismic event magnitude $(m)$ and MM intensity at the epicentre $\left(I_{0}\right)$ was given by Richter (1958):

$$
I_{0}=\frac{3}{2} m 1
$$

(equation 7)

\section{Maximum possible earthquake magnitude, $\boldsymbol{m}_{\max }$}

It is assumed, that in the area of concern, within a specified time interval $T$, there are $n$ main seismic events with magnitudes $m_{1}, m_{2}, \ldots, m_{\mathrm{n}}$. Each magnitude $m_{\mathrm{i}} \geq m_{\min }(\mathrm{i}=1, \ldots, \mathrm{n})$, where $m_{\min }$ is a known threshold of completeness (i.e., all events having magnitude greater than or equal to $m_{\min }$ are recorded). It is further assumed that the seismic event magnitudes are independent, identically distributed, random values with 


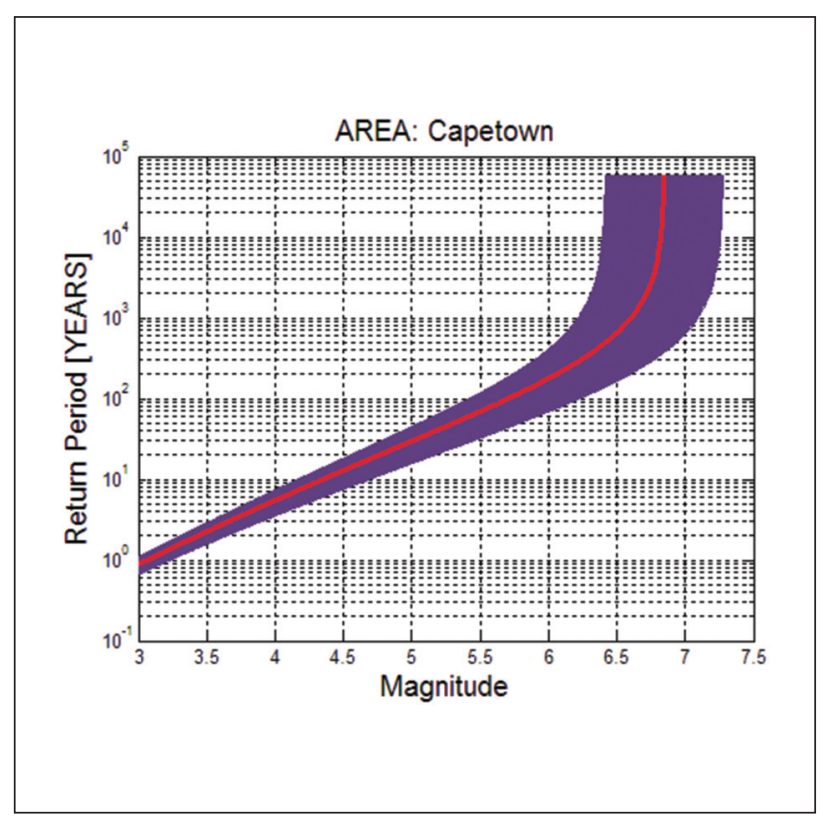

Figure 3. The mean return periods for earthquakes of specified magnitude for Cape Town. The red curve shows the mean return period, while the two blue curves indicate the mean return periods plus and minus the standard deviation.

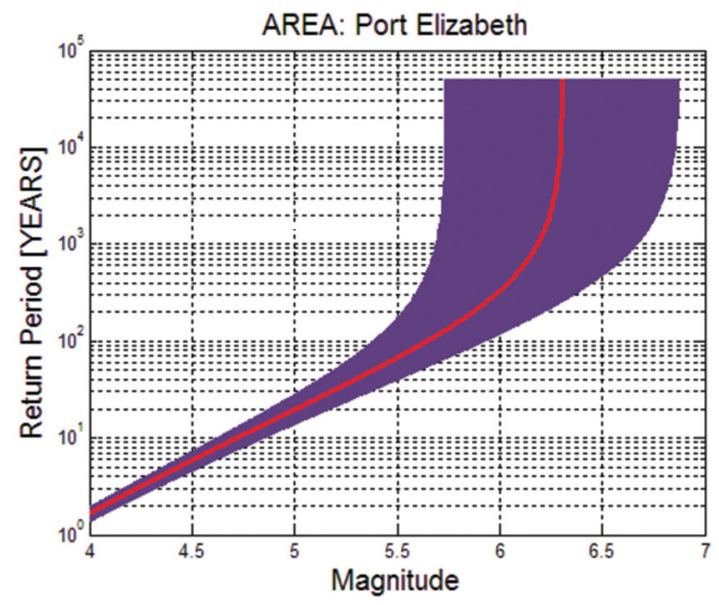

Figure 5. The mean return periods for earthquakes of specified magnitude for Port Elizabeth. The red curve shows the mean return period, while the two blue curves indicate the mean return periods plus and minus the standard deviation.

a known distribution function $F_{\mathrm{M}}(m)$. The parameter $m_{\max }$ is the upper limit of the range of magnitudes and thus denotes the unknown maximum regional magnitude which is to be estimated.

Given the importance of the $m_{\max }$ value, it is surprising how little has been done in developing appropriate techniques for estimating this parameter. Presently, there is no universally accepted technique for

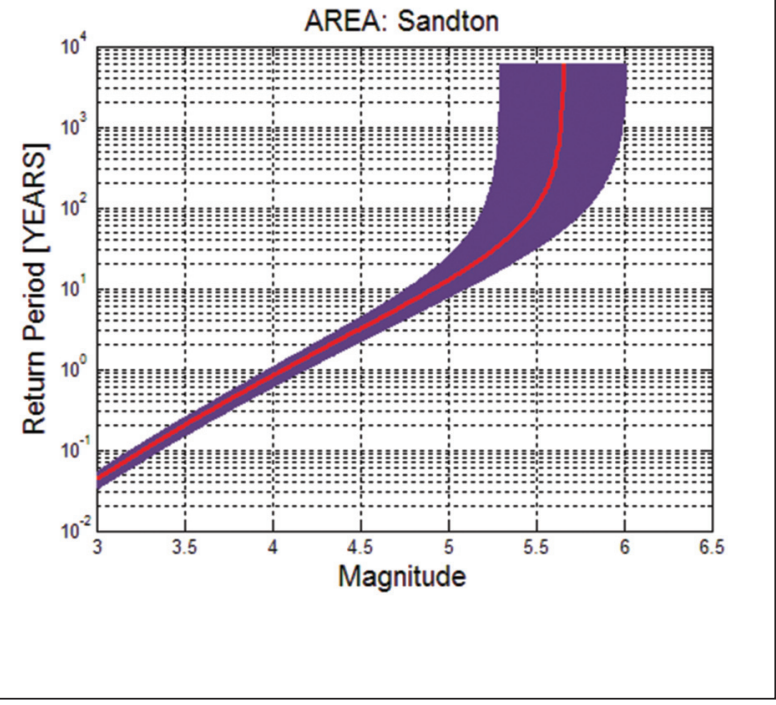

Figure 4. The mean return periods for earthquakes of specified magnitude for Sandton. The red curve shows the mean return period, while the two blue curves indicate the mean return periods plus and minus the standard deviation.

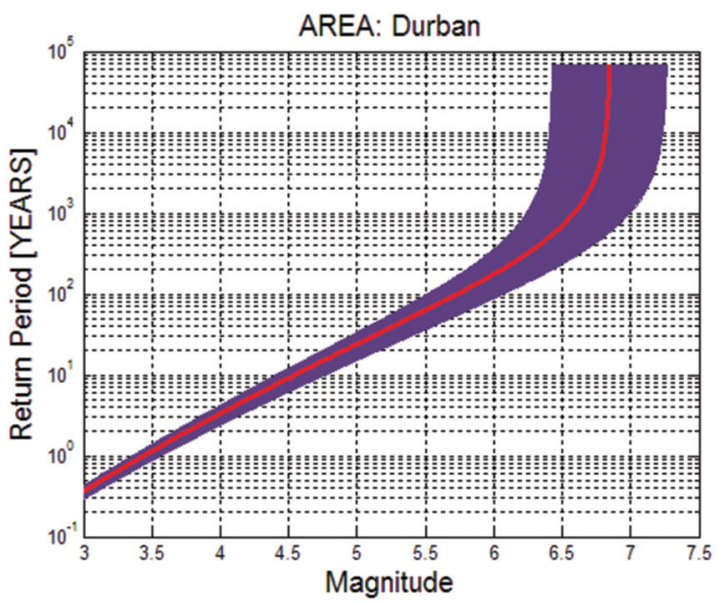

Figure 6. The mean return periods for earthquakes of specified magnitude for Durban. The red curve shows the mean return period, while the two blue curves indicate the mean return periods plus and minus the standard deviation.

estimating the value of $m_{\max }$. However, Wells and Coppersmith (1994), Wheeler (2009), and Mueller (2010) described deterministic techniques for its assessment, while Kijko (2004) and Kijko and Singh (2011) presented probabilistic techniques. The importance of the correct assessment of the regional-characteristic, maximum possible earthquake magnitude, $m_{\max }$, is that it is pivotal in seismic risk assessments as this value can be the 
Table 1. Area-characteristic seismic hazard parameters estimated for the city of Cape Town, Sandton, Port Elizabeth and Durban.

\begin{tabular}{|c|c|c|c|}
\hline Region/City & $\begin{array}{l}\text { Regional maximum possible } \\
\text { earthquake magnitude } m_{\max }\end{array}$ & $\begin{array}{l}\text { Gutenberg-Richter } \\
\text { parameter, } b \text {-value }\end{array}$ & Mean annual activity rate $\lambda$ \\
\hline Cape Town & $6.85 \pm 0.60$ & $0.84 \pm 0.08$ & $1.1 \pm 0.3\left(\right.$ for $\left.m_{\min } \geq 3.0\right)$ \\
\hline Sandton & $5.66 \pm 0.36$ & $1.40 \pm 0.04$ & $23.3 \pm 5.9\left(\right.$ for $\left.m_{\min } \geq 3.0\right)$ \\
\hline Port Elizabeth & $6.31 \pm 0.57$ & $1.13 \pm 0.09$ & $0.6 \pm 0.1\left(\right.$ for $\left.m_{\min } \geq 4.0\right)$ \\
\hline Durban & $6.85 \pm 0.60$ & $1.03 \pm 0.06$ & $2.8 \pm 0.5\left(\right.$ for $\left.m_{\min } \geq 3.0\right)$ \\
\hline
\end{tabular}

difference between life and death for large numbers of people. The methodology and assumptions for estimating $m_{\max }$ used in this study is described thoroughly by Kijko and Singh (2011).

Seismic events were selected from the South African National Seismological Database (SANSD) of earthquakes that occurred between 1811 and 2012. The data used in this study were compiled by the Council for Geoscience, Pretoria. All earthquakes are expressed in the units of local Richter magnitude, $M_{\mathrm{L}}$. The procedures used in calculating the $m_{\max }$ value were developed in a MATLAB toolbox called MMAX (Kijko and Singh, 2011).

The actual computation for $m_{\max }$ is based on the application of the Kijko-Sellevoll-Bayes procedure, which takes into account incompleteness and uncertainty of seismic event catalogues (Kijko and Sellevoll, 1992). The results of the computation are shown in Figures 3, 4, 5 and 6, for Cape Town, Sandton, Port Elizabeth and Durban respectively. The obtained parameters including $m_{\max }$ for the four cities are shown in Table 1.

\section{Computation of expected damage for most typical urban structures in South Africa}

Vulnerability assessments were done for the most prevalent of the 12 types of building classes of South Africa as defined by Davis and Kijko (2003) and Pule et al. (2006). The assessments were performed for the four cities, and 3 classes of the buildings, building class \#3 (unreinforced masonry, bearing wall, low rise), \#8 (reinforced concrete shear wall, without moment resisting frame, medium rise) and $\# 9$ (reinforced concrete shear wall, without moment resisting frame, high rise). Following Davis and Kijko (2003), these are the most common structures in South African urban areas. These three building types represent ca. $70 \%$ of all South African urban structures and Class \#3 represents low cost housing typical for e.g. South Africa coastal areas.

Building vulnerability is a measure of the damage a building is likely to experience when it is subjected to a specific level of ground shaking (for example, in terms of peak ground acceleration, peak ground displacement, or earthquake intensity). The dynamic response of a structure to ground shaking is very complex, and depends on a number of interrelated factors that are often very difficult, if not impossible, to identify precisely. These include:

- the exact character of the ground movement and the shaking the building will experience;
- the extent to which the structure will be excited and

- the response to the ground shaking;

- the strength of the materials in the structure;

- the quality of construction;

- the condition of individual structural elements and of the whole structure;

- the interaction between structural and non-structural elements;

- the live load present in the building (occupancy etc. at the time of the earthquake; other factors (Omidvar et al., 2012).

In this study only nature of ground movement and shaking the building is likely to experience is considered and presented.

For each selected site, four epicentral distances, 10, 25, 75 and $100 \mathrm{~km}$, are considered. The earthquake magnitudes $m_{\max }$ are given in Table 1 . The output from the analysis of each combination of epicentral distance, magnitude and class of the building is the expected damage to structure (in \%), known also as a central damage factor

The estimated expected damage for the three selected building classes is shown in Figures 7 to 18. The vertical black line shows the estimated MM intensity at the site. The horizontal black line denotes respectable expected damage to the structure. The results confirm that there is an inverse relationship between distance from the earthquake epicenter and inflicted damage, (horizontal black lines in figures 7 to 18). However, it should be noted that different building classes withstand/absorb the movement and forces due to the shaking differently, given the different building design principles for each class of building. For example, a reinforced building can withstand earthquake caused ground vibration better than an unreinforced building.

\section{Discussion of the estimated damage: Cape Town}

The predicted damage for building class \#9 is the lowest, while building class $\# 3$ is expected to experience the highest damage at all distances. The damage to this class of the buildings is approximately equal to $47 \%$ where the epicentral distance is $10 \mathrm{~km}$. Therefore, building class \#3 is the most vulnerable in Cape Town. This is a large concern as the majority of the large volume, low cost housing in the disadvantaged areas on the "Cape Flats" such as Manenberg (Figure 19), is of this type. 

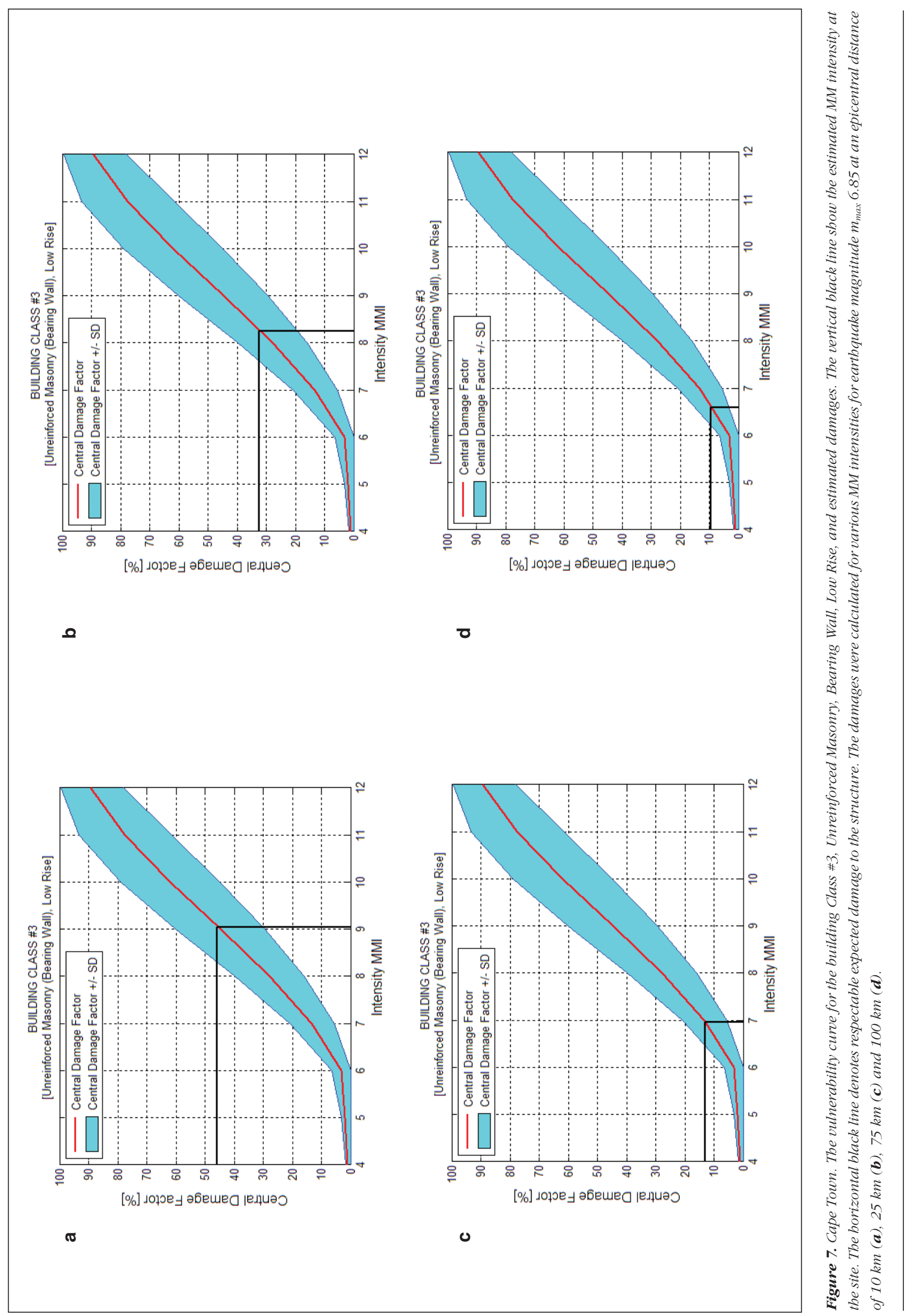

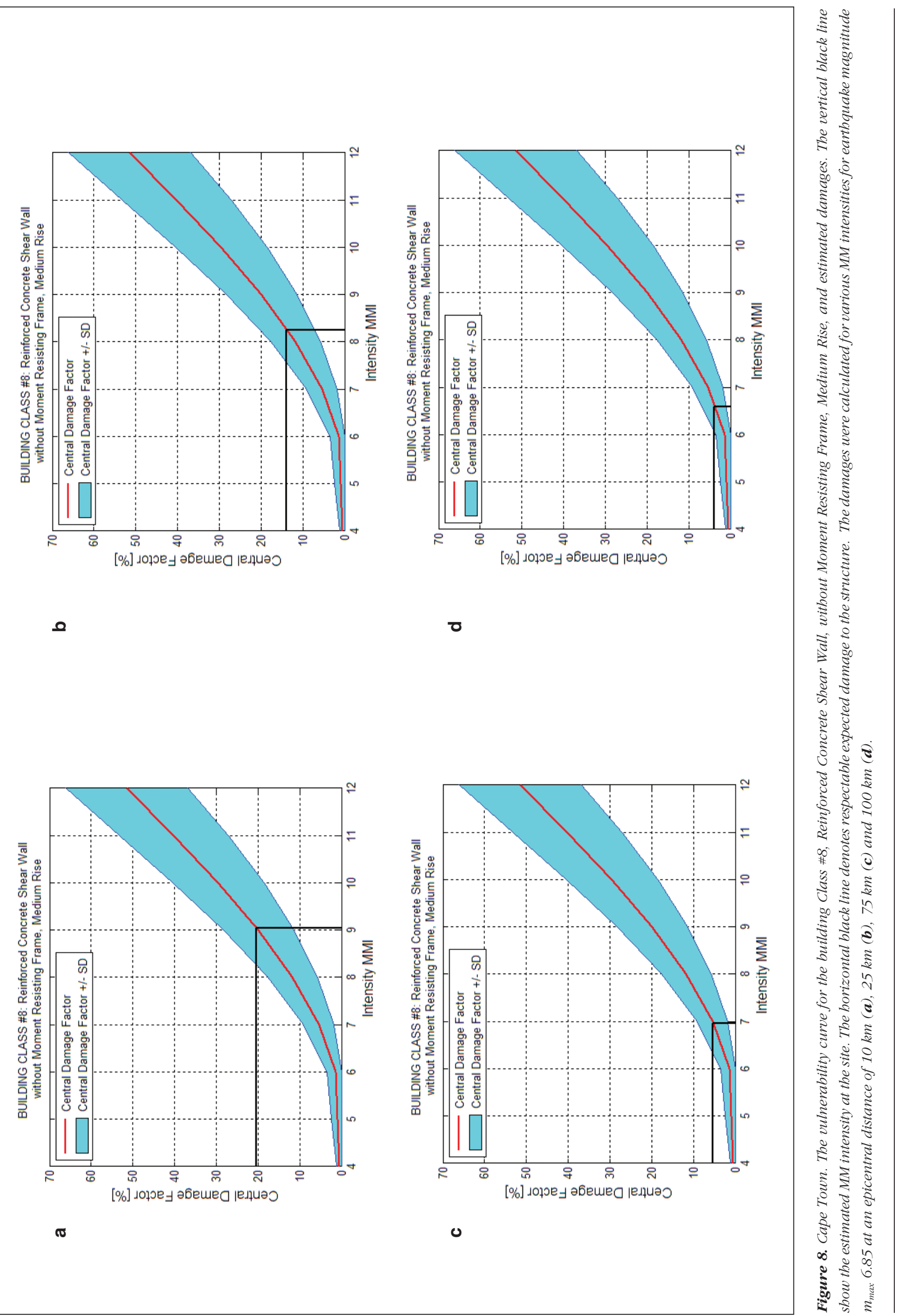

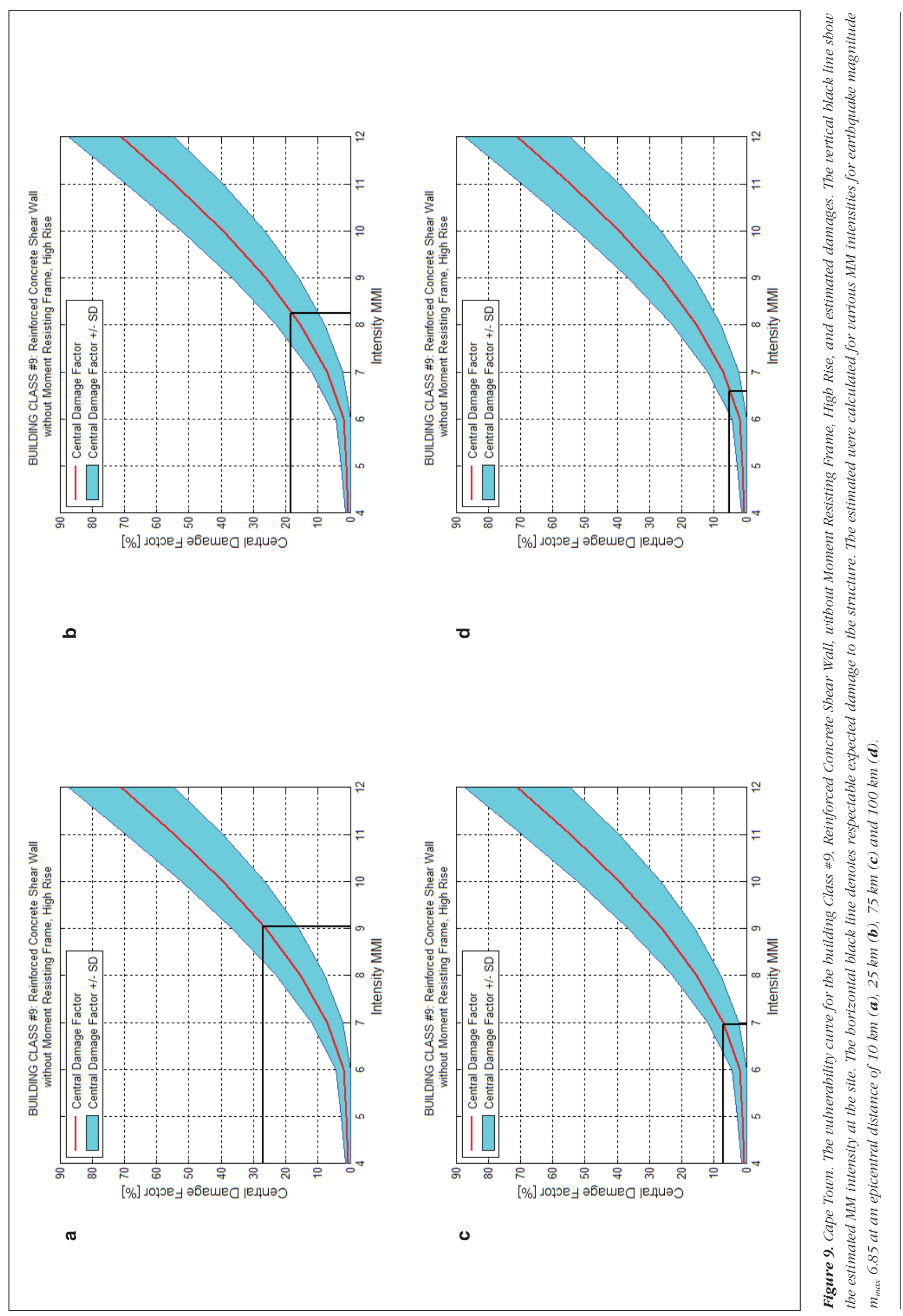


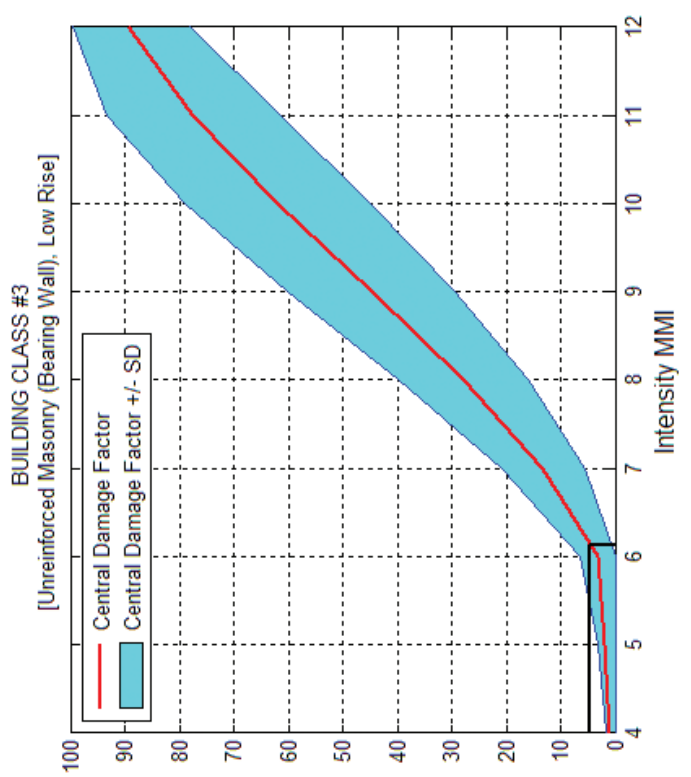

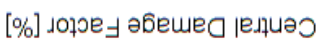

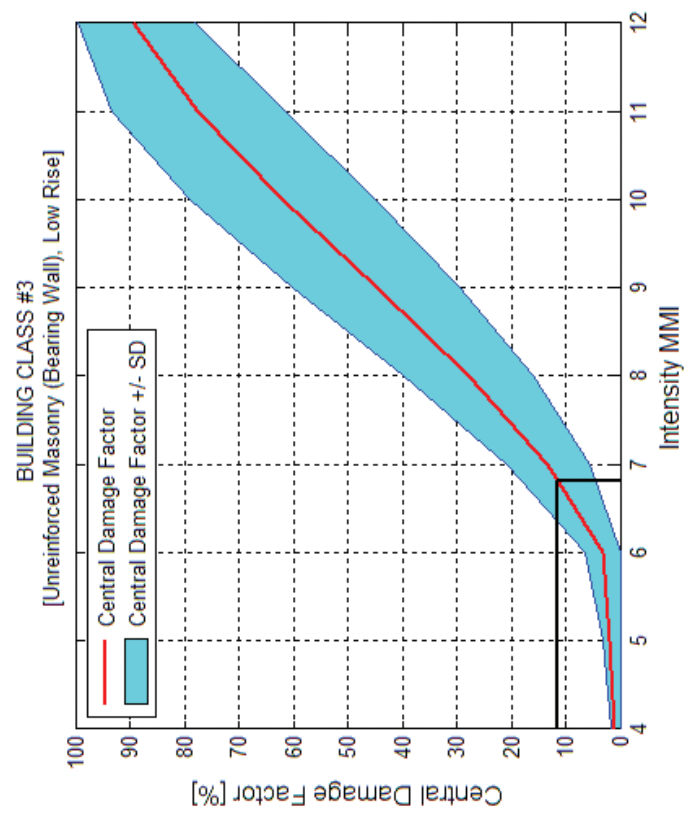

ช

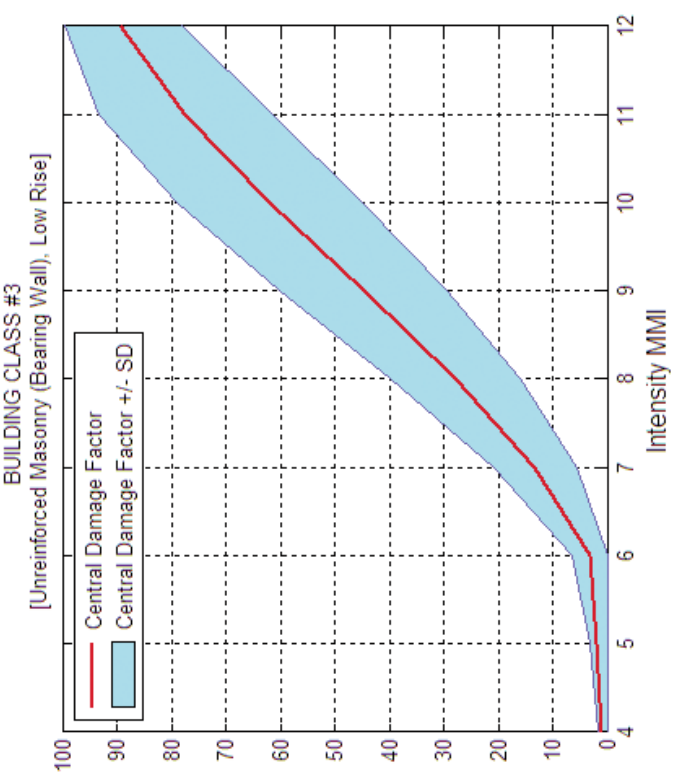

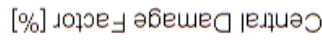

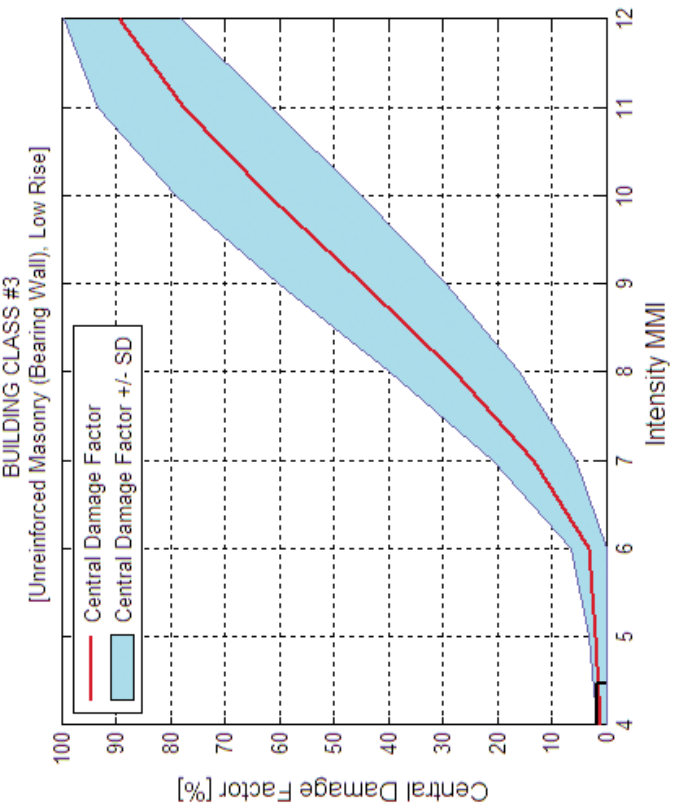

0

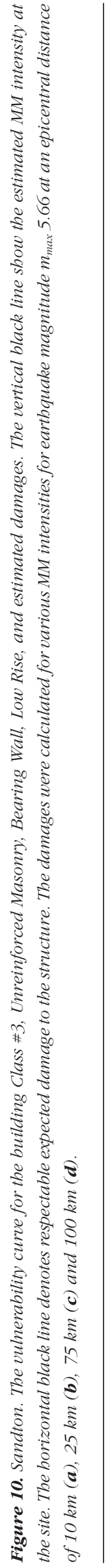

SOUTH AFRICAN JOURNAL OF GEOLOGY 

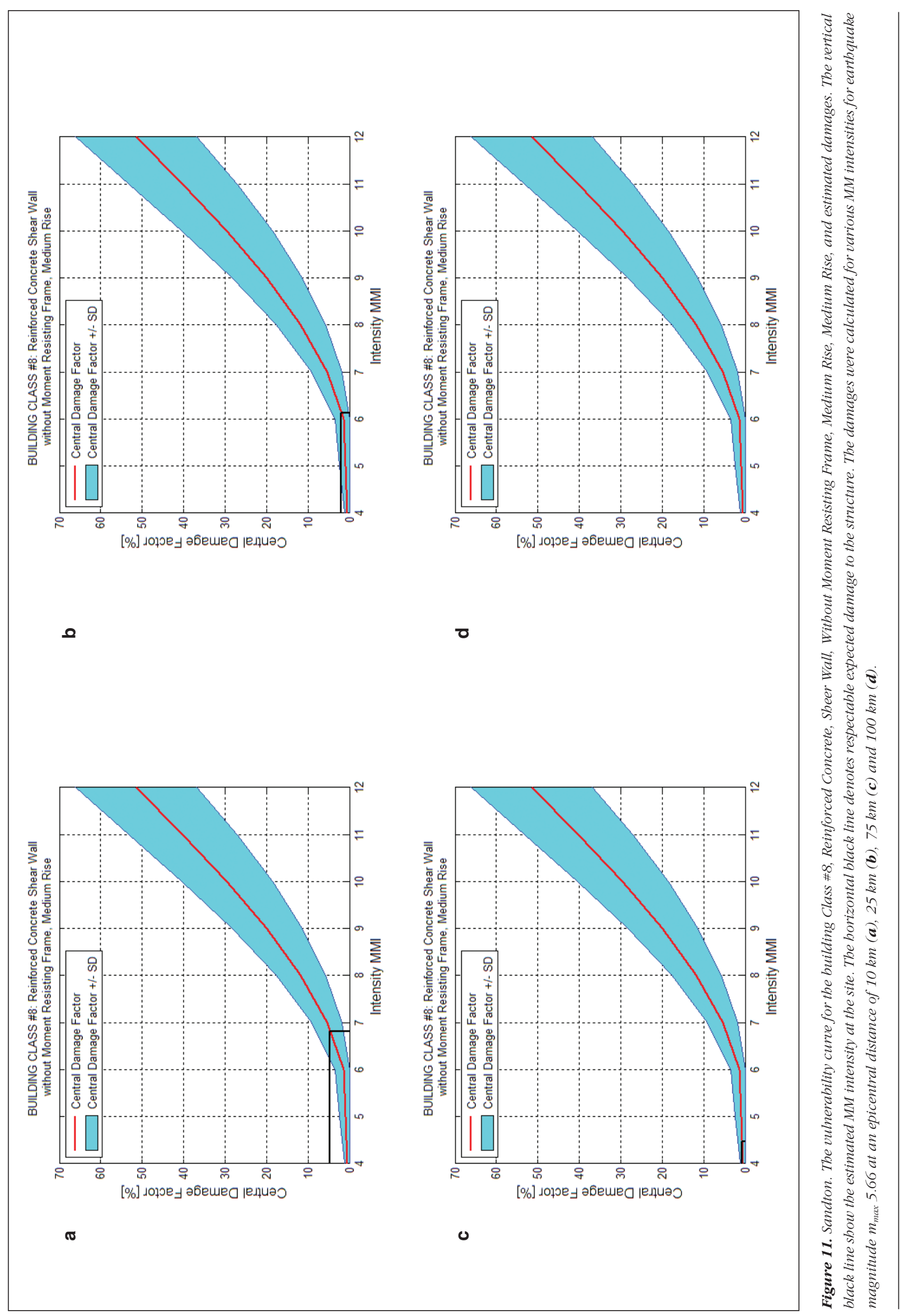

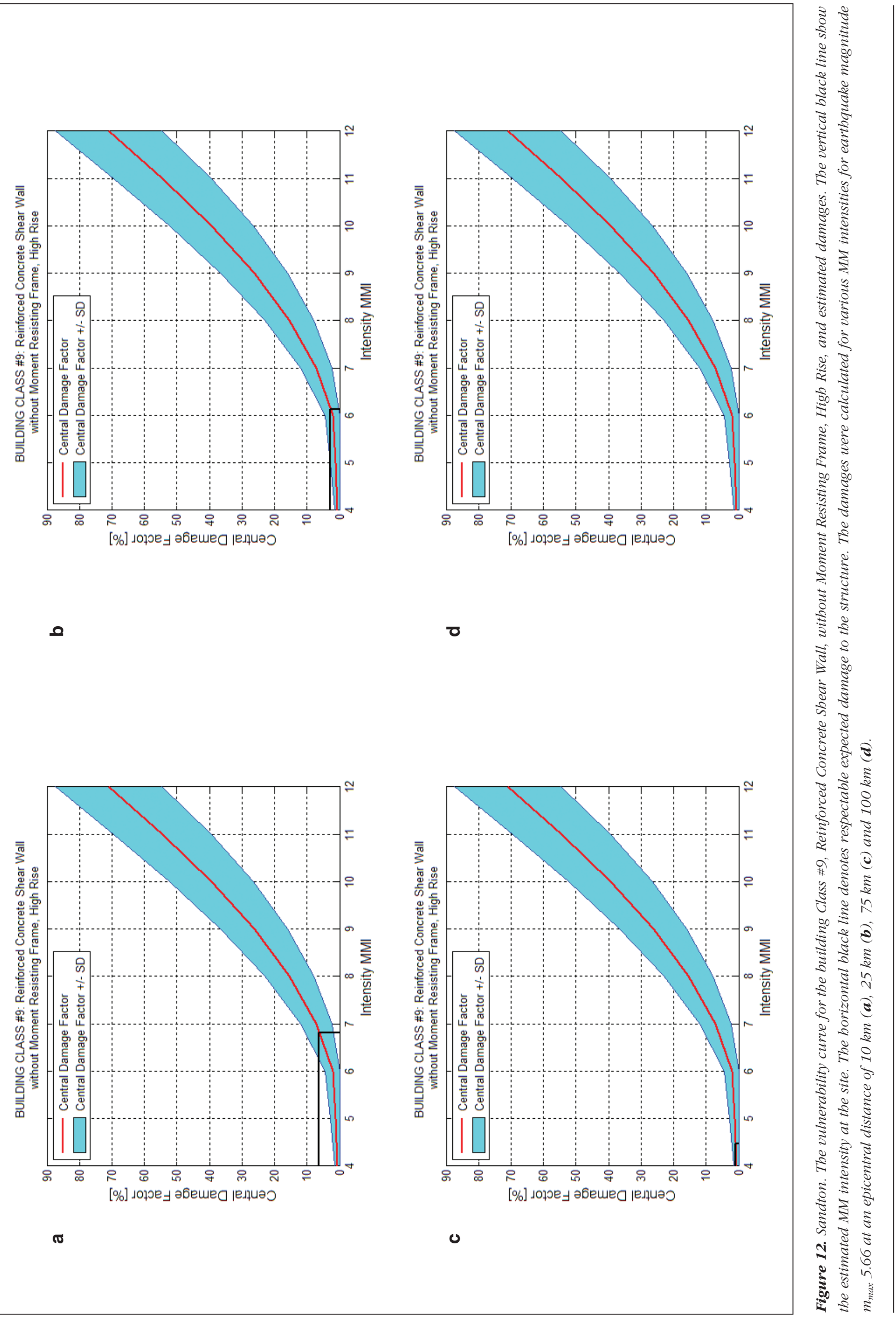

ช 


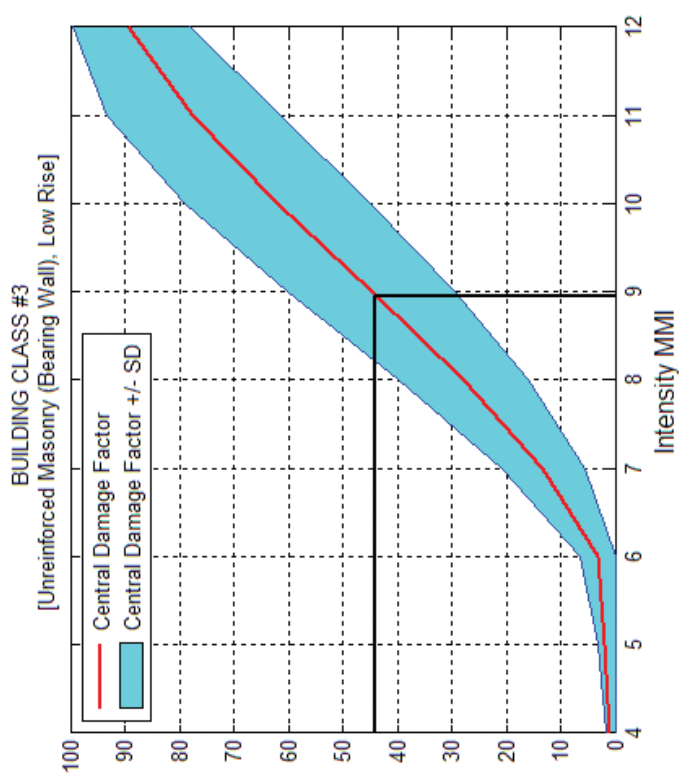

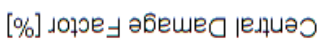

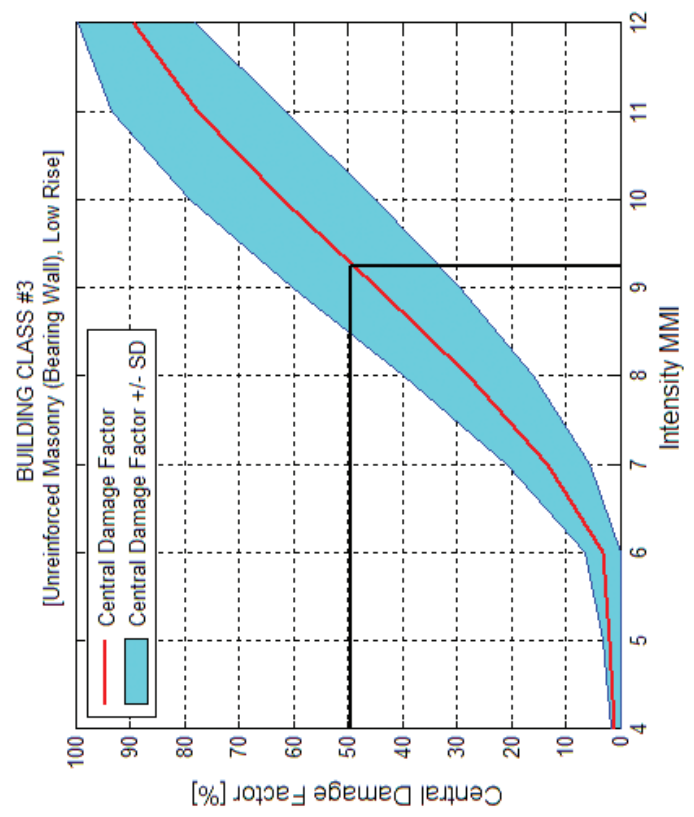

ช

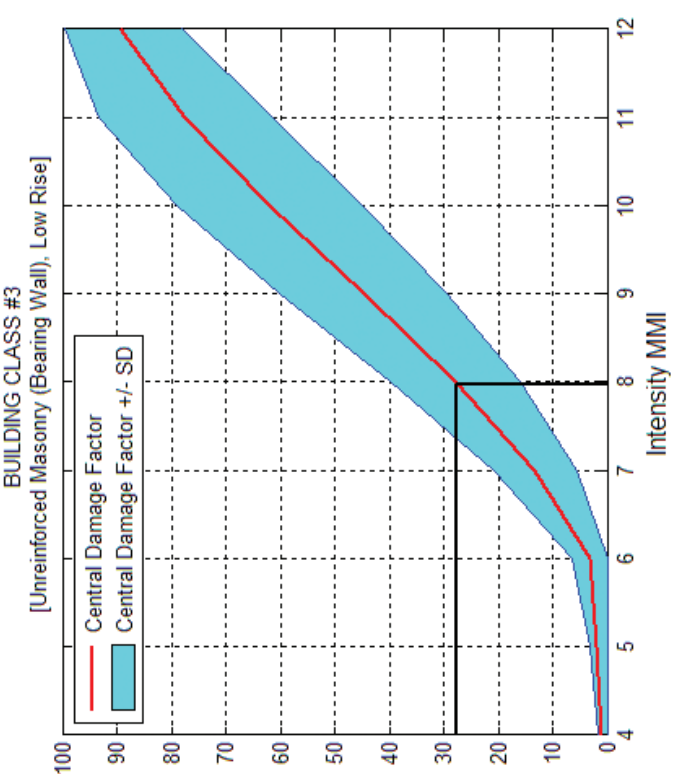

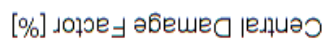

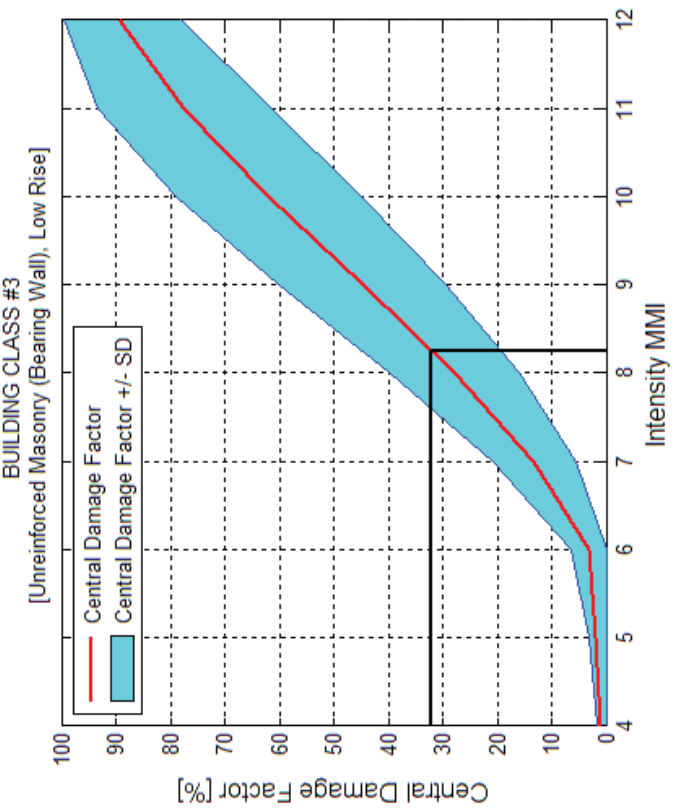

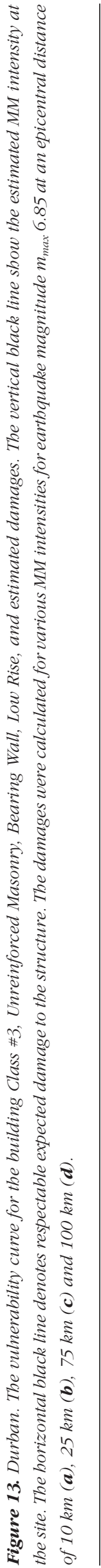



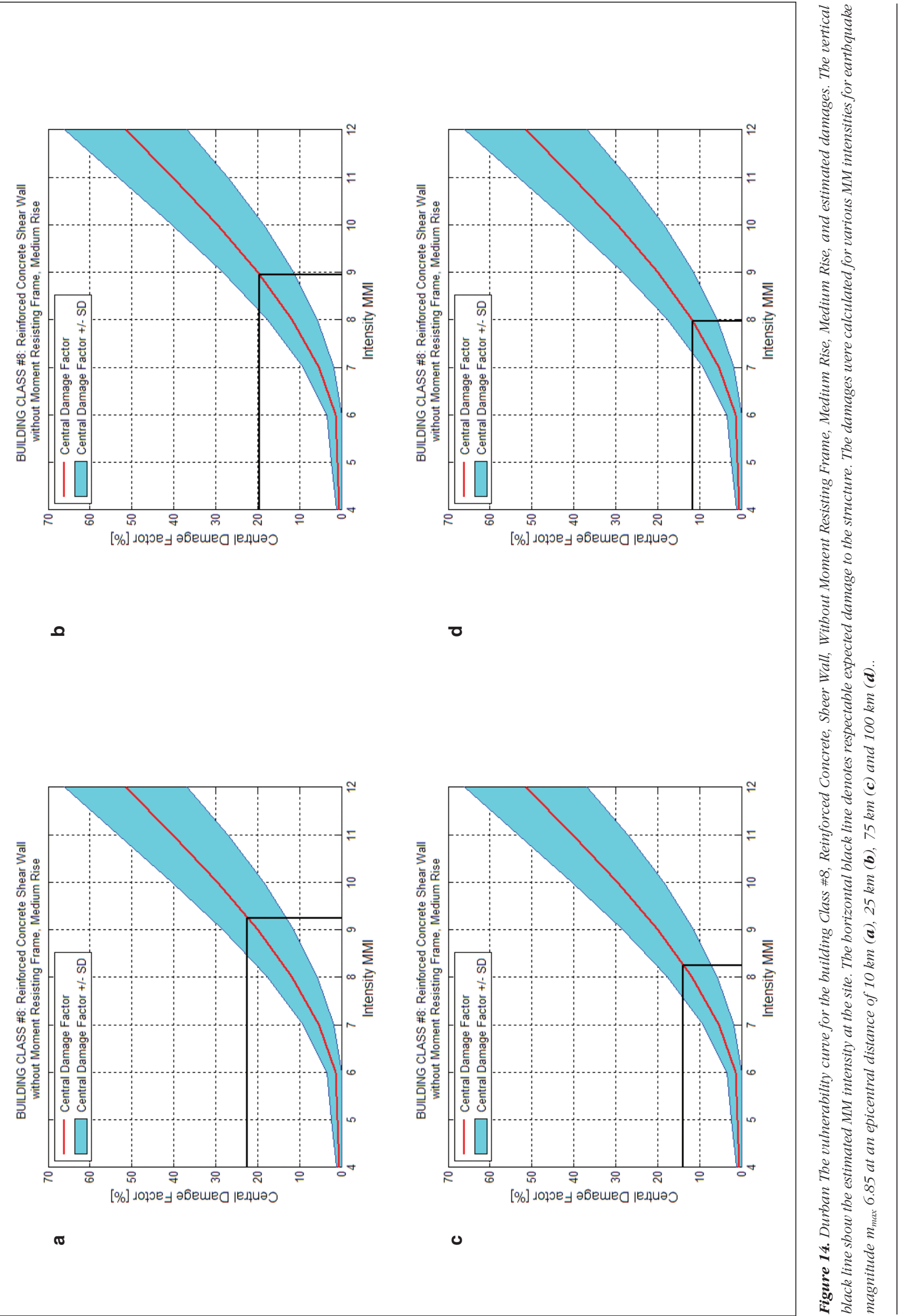

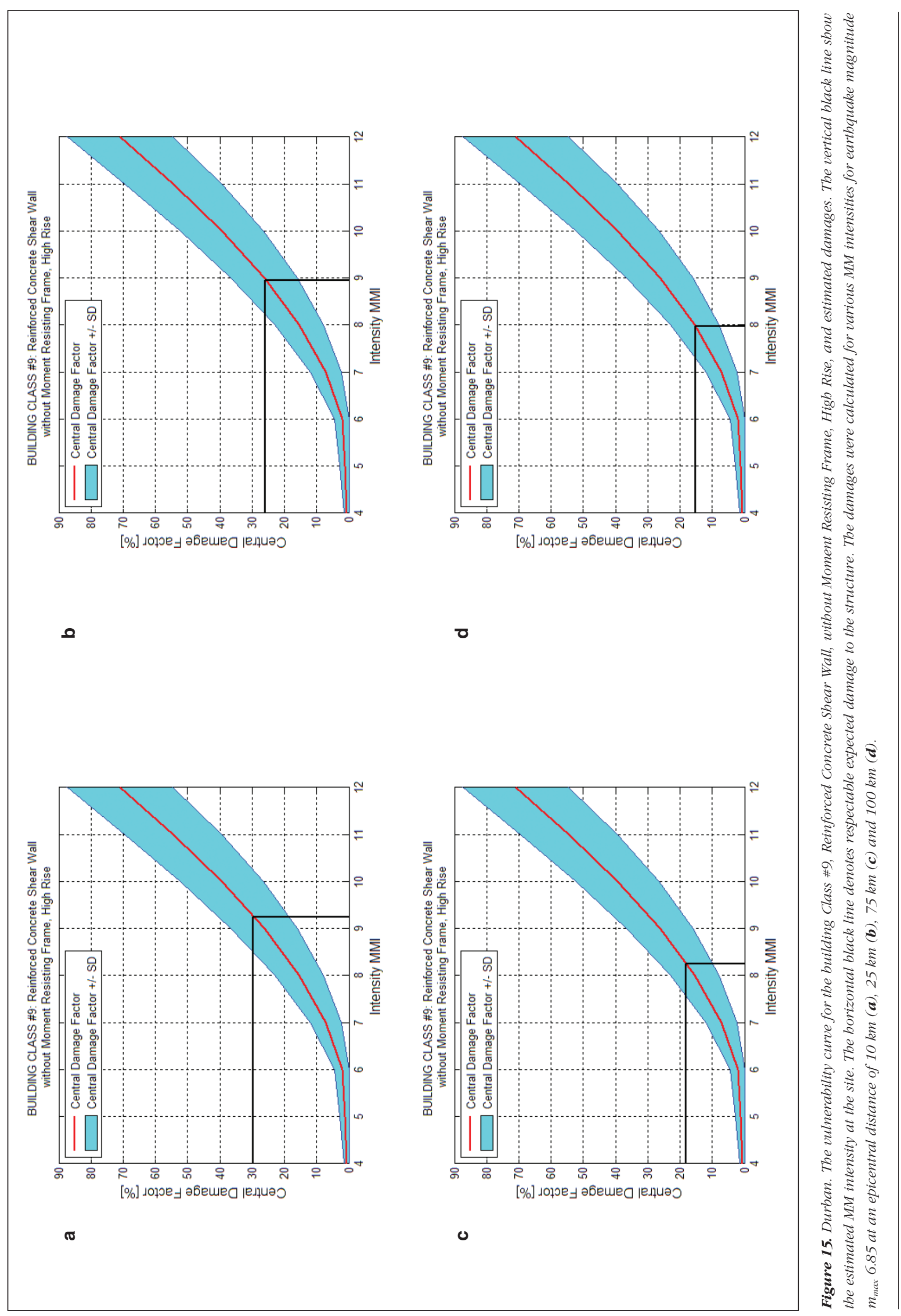


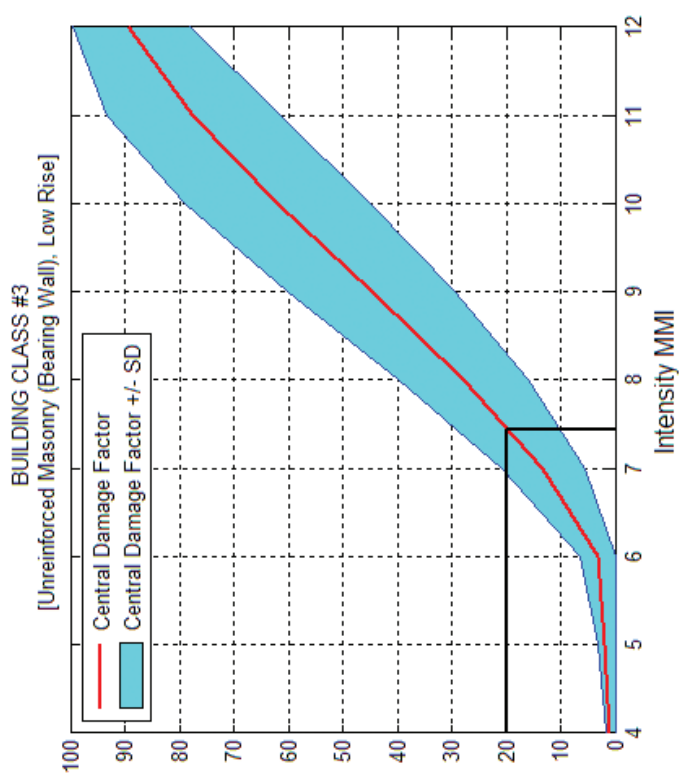

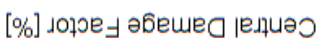

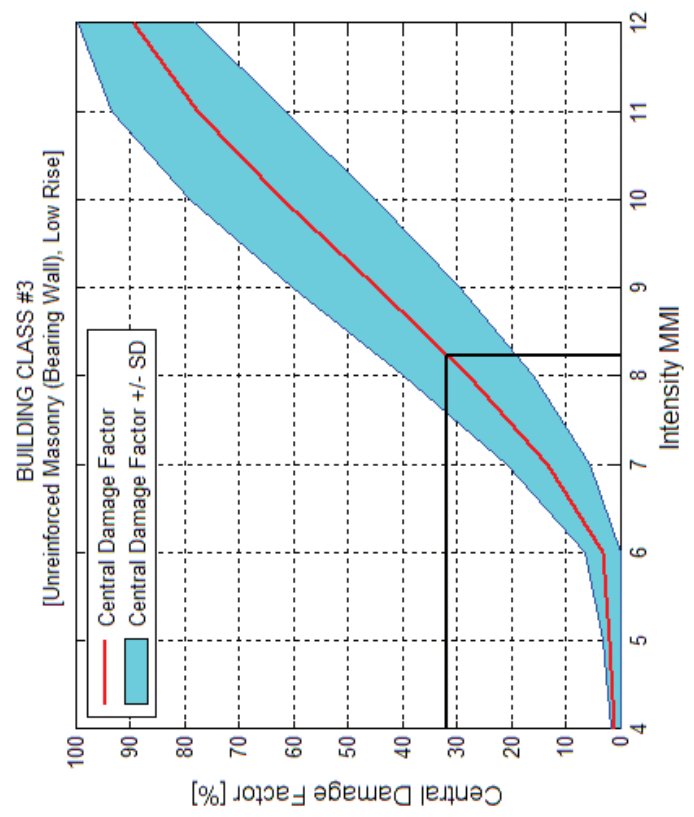

ช

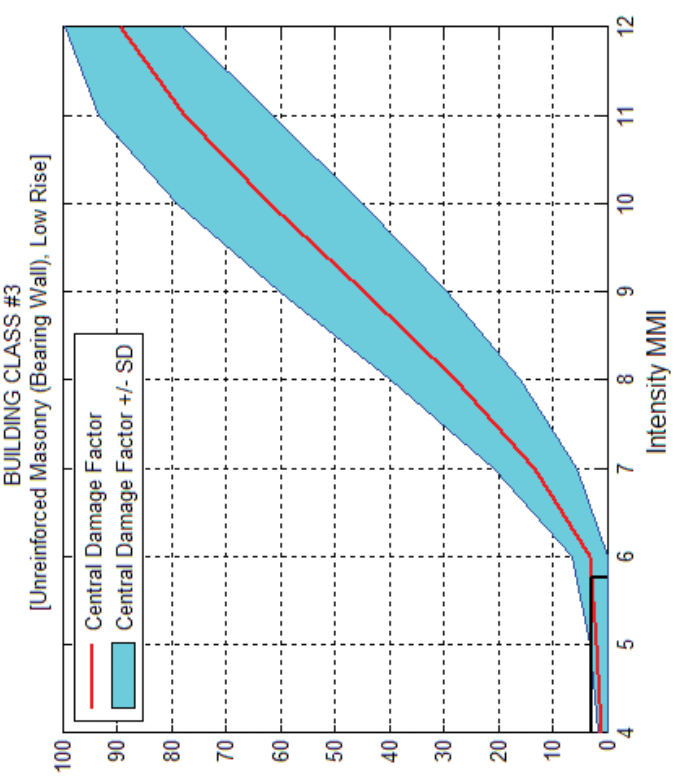

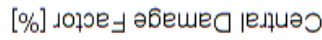

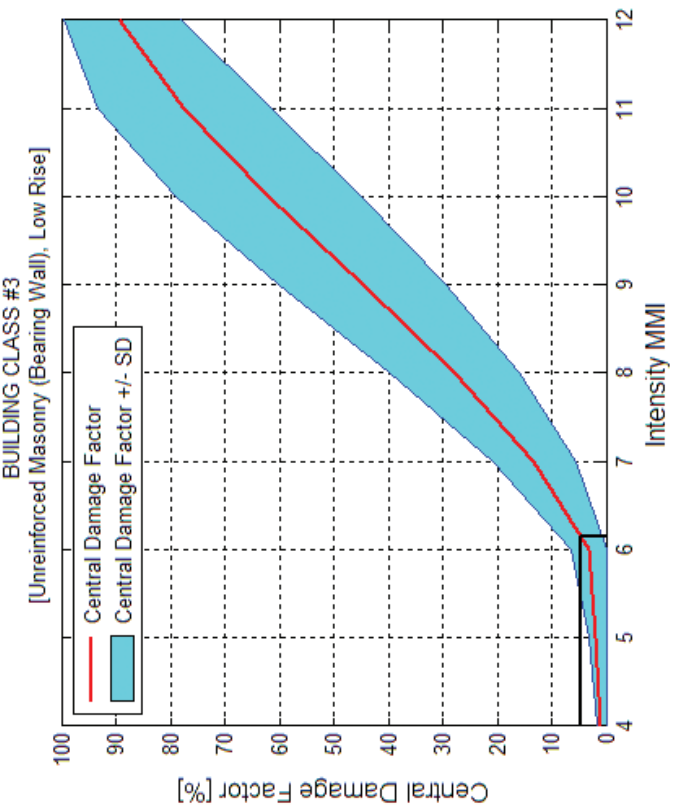



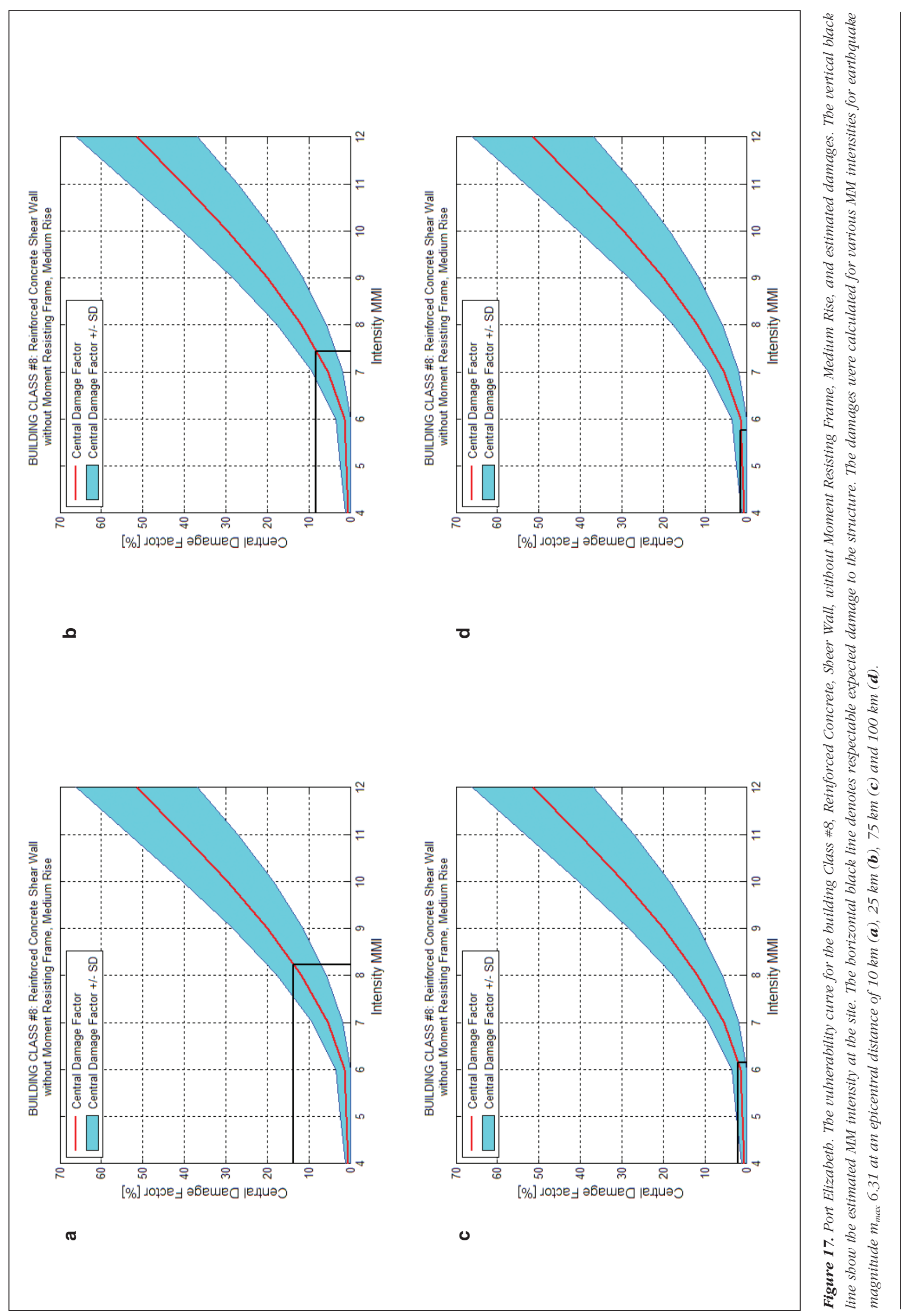

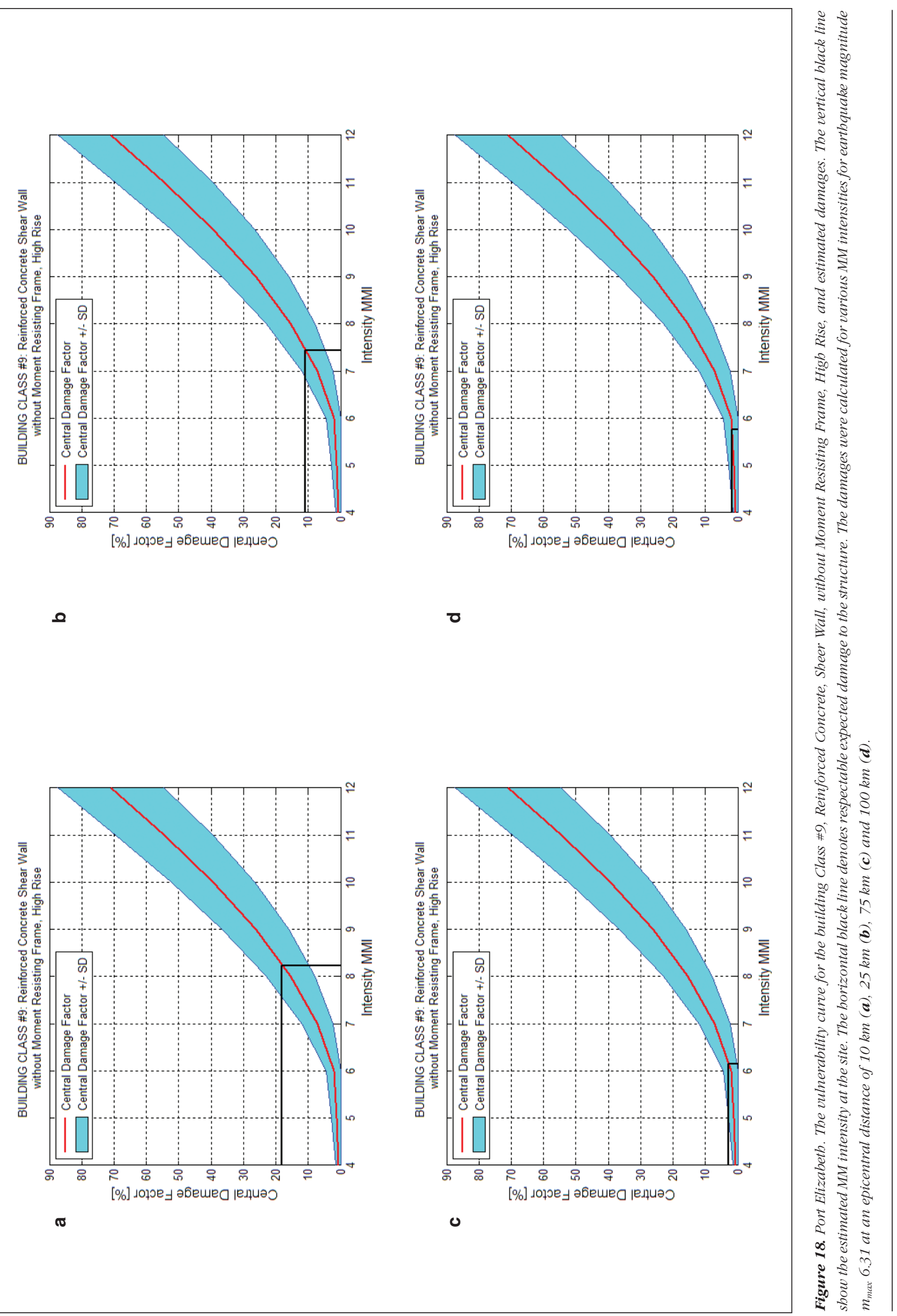


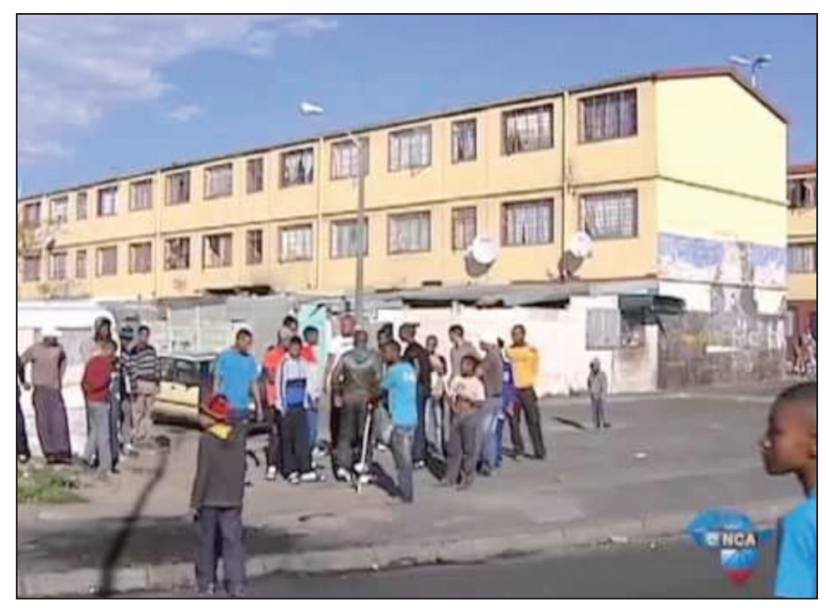

Figure 19. Example of large scale low cost housing (Class \#3) found in Manenberg on the Cape Flats, Tongaat near Durban and Zwide near Port Elizabeth.

\section{Durban}

The predicted damage for building class \#9 is the lowest while the highest damage for all distances is also expected to affect building class \#3. Building class \#3 is the most vulnerable in the Durban area. As in Cape Town, this is a major concern as the majority of the large volume, low cost housing in the areas such as Tongaat near Durban (Figure 19), is of this type. An additional concern in Durban is that bedrock is overlain by thick sandy cover which increases the possibility of site amplification.

\section{Sandton}

- At epicentral distance of $10 \mathrm{~km}$, building class \#9 is subject to the lowest degree of damage and building class \#3 to the highest. However, the expected damage to building class \#3 is only $12 \%$ when the epicentre is $10 \mathrm{~km}$ away reducing to less than $1 \%$ if the epicentre is $100 \mathrm{~km}$ away. This means that the impact on low cost housing for Sandton is not that severe.

- At a distance of $25 \mathrm{~km}$, building Class \#9 has the lowest expected damage and building Class \#3 the highest degree of damage.

- At $75 \mathrm{~km}$, the lowest degree of damage is associated with building Class \#9 and the highest degree with building Class \#3.

- The predicted damage to all considered classes of buildings at distance of $100 \mathrm{~km}$ is negligible.

\section{Port Elizabeth}

- For all epicentral distances, the predicted damage for building Class \#9 is of the lowest, while building Class \#3 is predicted to experience the highest degree of damage. At short distances, the predicted damage can be as high as 32\%. As in Cape Town, this is a major concern as the majority of the large volume, low cost housing in the areas such as Zwide near Port Elizabeth (Figure 19), is of this type.
- Building Class \#9 is the least vulnerable and building Class \#3 the most vulnerable at $75 \mathrm{~km}$ distance.

It should be noted that the expected damage of the structure increases as the MM intensity increases, and as the epicentral distance decreases. Buildings experience more damage at the closest distance from the earthquake epicentre, because of the higher intensity of ground vibration. However, the expected damage also depends on the type of building. The predicted damage for building Class \#3 is the highest in all analysed areas. One has to remember, that this class of building is one of the most common structures in South African urban areas.

\section{Conclusion and recommendations}

Potential damage that can be caused by strong earthquakes was estimated for 3 types of buildings situated in Sandton, Cape Town, Durban and Port Elizabeth. The analysis was performed by considering the "worst case-scenario", i.e. occurrence of the maximum possible earthquake close to structures. The Modified Mercalli intensity scale was used as a measure of ground motion vibration. The MM intensity was chosen, because (1) the applied damage curves (ATC-13, 1985), describe the expected damage to the structures as a function of intensity, and (2) application of area-characteristic GMPEs allows for account of site effect. In four studied urban areas, Sandton, Cape Town, Port Elizabeth and Durban, expected damage was estimated for three classes of buildings: unreinforced masonry, bearing wall, low rise (class \#3); reinforced concrete shear wall, without moment resisting frame, medium rise (class \#8), and the reinforced concrete shear wall, without moment resisting frame, high rise (class \#9). The results of our analysis showed that when strong earthquakes occur, significant damage is expected for building class \#3 with the highest damage at all distances for all four cites. Area characteristic, maximum possible earthquake magnitude values $m_{\max }$ were used together with a region specific GMPE equation (determined for Modified Mercalli intensity) for epicentre distances of 10, 25, 75 and $100 \mathrm{~km}$, to compute the expected damage curves.

Since the South African government is investing a large amount of the annual budget into the national housing scheme, these results are vital in the design and construction of the current low cost housing investment by the government. This study shows that low cost housing, especially in the coastal areas should be redesigned to withstand possible earthquake damage to protect this huge investment and in the process reduce the risk of loss of life.

\section{Acknowledgments}

The authors are grateful to the referees Drs L. Linzer and E.H. Stettler whose constructive comments have helped improve the paper greatly. 


\section{References}

Applied Technology Council, ATC-13, 1985. Earthquake Damage Evaluation Data for California. Applied Technology Council, Redwood City, California, U.S.A., 167-221

Bramerini, F., Di Pascale, G., Orsini, G., Pugliese, A., Romeo, R. and Sabetta, F., 1995. Seismic Risk in territory of Italy. (in Italian) Proceedings of 7 th Convegno Nazionale di Ingegneria Sismica, Siena, Italy, 25 to 28 September, 1995.

Carnahan, B., Luther, H.A. and Wilkes, J.O., 1969. Applied Numeral Methods. John Wiley and Sons, New York, USA. 604pp.

Chen, Q., Chen, Y., Liu, J. and Chen, L., 1997. Quick and approximate estimation of earthquake loss based on macroseismic index of exposure population. Natural Hazards, 15, 217-29.

D'Ayala, D., Spence, R. and Oliveira, C., 1997. Earthquake loss estimation for Europe's historic town centres. Earthquake Spectra, 13, 773-93.

Davies, N. and Kijko, A., 2003. Seismic risk assessment: with an application to the South African insurance industry. South African Actuarial Journal, SAAJ, 3, 1-28.

Dowrick, D. and Rhoades, D.A., 1990. Damage ratios for domestic buildings in the 1987 Edgecumbe earthquake. Bulletin of the New Zealand National Society for Earthquake Engineering, 23, 137-49.

Dowrick, D. and Rhoades, D. A., 1993. Damage costs for commercial and industrial property as function of intensity in the 1987 Edgecumbe earthquake. Earthquake and Structural Damage, 22, 869-84.

Durrheim, R.J., Anderson, R.L., Cichowicz, A., Ebrahim-Trollope, R., Hubert, G., Kijko, A., McGarr, A., Ortlepp, W.D. and Van der Merwe, N., 2007. Investigation into the Risks to Miners, Mines, and the Public Associated with Large Seismic Events in Gold Mining Districts, Volume 2, Department of Minerals and Energy. South Africa, 33-40.

FEMA, 1994. Assessment of the State-of-the-Art Earthquake Loss Estimation Methodologies. Federal Emergency Management Agency, FEMA-249/June 1994, Earthquake Hazard Reduction Series 70, 300pp.

Fernandez, L.M., 1974. Some earthquake-resistant buildings recommendations, Seismological series 4. Geological Survey South Africa, Pretoria.

Joubert, A., Beukes, G.J., Visser, J.N.J. and de Bruin, H., 1991. A note on fluorite in Late Pleistocene thermal spring deposits at Florisbad, Orange Free State. South African Journal of Geology, 94, 174-177.

Kijko, A. and Sellevoll, M.A., 1992. Estimation of earthquake hazard parameters from incomplete data files. Part II. Incorporation of magnitude heterogeneity. Bulletin of the Seismological Society of America, 82(1), 120-134, February 1992

Kijko, A. and Singh, M., 2011. Statistical Tools for Maximum Possible Earthquake Magnitude Estimation. Acta Geophysica, 59(4), August 2011, 674-700.

Kijko, A., 2004. Estimation of the Maximum Earthquake Magnitude, $m_{\max }$. Pure appl. geophys. 161, 1-27.

Kijko, A., 2011. Seismic Hazard in Encyclopedia of Solid Earth Geophysics Vol 1 (1st Edition). Edited by H.K. Gupta. Springer, 1107-1120.

Kijko, A., Hattingh, E., Ramperthap, J., Bejaichund, M. and Pule, T., 2006. Deterministic Seismic Hazard and Risk Program (D-SHARP): Intensity Attenuation Models and Vulnerability Curves for South Africa, Council For Geoscience South Africa, Report, 2006-0264.

Kijko, A., Retief S.J.P. and Graham, G., 2003. Seismic hazard and risk assessment for the Tulbagh, South Africa: Part II - Assessment of seismic risk. Natural Hazards, 30, 25-41.

Kijko, A., Retief, S.J.P. and Graham, G., 2002. Seismic hazard and risk assessment for the Tulbagh Area, Part I. Assessment of Seismic Hazard. Natural Hazards, 26, 175-201.

Midzi, V., Zulu, B., Manzunzu, B., Mulabisana, T., Pule, T., Myendeki, S., and Gubela, W., 2015 Macroseismic survey of the ML5.5, 2014. Orkney earthquake, Journal of Seismology, 19(3), 741-751.
Mueller, C.S., 2010. The influence of maximum magnitude on seismic-hazard estimates in the central and eastern United States, Bulletin of the Seismological Society of America, 100(2), 699-711, DOI: 10.1785/0120090114.

Omidvar, B., Gatmiri, B. and Derakhshan, S., 2012. Experimental vulnerability curves for the residential buildings of Iran. Natural Hazards (2012), 60, 345-365.

Orsini, G., 1999. A model for buildings' vulnerability assessment using the parameter less scale of seismic intensity. Earthquake Spectra, 15, 463-83.

Peruzza, L., 1996. Attenuating intensities. Annali Di Geofisica, Vol XXXIX, 5, 1079-1093.

Pule, T. and Singh, M., 2010. Evaluation of awareness of earthquakes and earthquake-resistant design in the South African construction industry: report on questionnaires. Council For Geoscience, South Africa, Report 2010-0076.

Reitherman, R., 1985. A review of earthquake damage estimation methodologies. Earthquake Spectra, 1, 805-47.

Richter, C.F. 1958, Elementary Seismology, W.H. Freeman and Company, San Francisco, 136-139.

Rojahn, C., King, S. A., Scholl, R.E., Kiremidjian, A.S., Reaveley, L.D. and Wilson, R.R., 1997. Earthquake damage and loss estimation methodology and data for Salt Lake County, Utah (ATC-36). Earthquake Spectra: November 1997, 13(4), 623-642.

Shojgu, S.K., Shakhramanjyan, M.A., Koff, G.L., Kenzhebaev, E.T., Larionov, V.I., and Nigmetov, G.M.: 1992, Seismic risk analysis, population rescue and life support during catastrophic earthquakes (seismological, methodological and systematic aspects), 1/2, 295pp., in Russian, State Committee of Russian Federation on Civil Defense and Emergency Situations, Moscow.

Singh, M., Kijko, A. and Durrheim, R., 2009. Seismotectonic Models for South Africa: Synthesis of Geoscientific Information, Problems, and the Way Forward Seismological Research Letters, 80(1), January/February 2009, $71-80$.

Theron, J.N., 1974. "The seismic history of the Southwestern Cape Province". The earthquake of 29 September 1969 in the Southwestern Cape Province, South Africa. Seismologic Series, 4, Geological Survey, South Africa, 12-18.

Tyagunov, S., Grunthal, G., Wahlstrom, R., Stempniewski, L. and Zchau, J., 2006. Seismic risk mapping for Germany, Natural Hazards Earth System Sciences, 6, 573-586.

Visser, J.N.J. and Joubert, A., 1990. Possible earthquake-induced sediment liquefaction in thermal spring deposits at Florisbad, Orange Free State. South African Journal of Geology, 93, 525-530.

Wells, D.L. and Coppersmith, K.J., 1994. New empirical relationships among magnitude, rupture length, rupture width, rupture area, and surface displacement, Bulletin of the Seismological Society of America, 84, 974-1002.

Wheeler, R.L., 2009. Methods of $m_{\max }$ estimation east of the Rocky Mountains, United States Geological Survey Open-File Report 2009-1018, $44 \mathrm{pp}$.

Whitman, R.V., 1986, Earthquake Loss Estimation Methodology, In: A. Vogel and K. Brandes (Editors), Earthquake Prognostics, Hazard Assessment, Risk Evaluation and Damage Prevention, Proceedings from the 2nd International Seminar held in Berlin, June 24 to 27. Friedr. Vieweg and Sohn, Braunschweig/Wiesbaden, 259-278.

Whitman, R.V., Reed, J.W. and Hong, S.T., 1973. Earthquake Damage Probability Matrices, Proceedings of the Fifth World Conference on Earthquake Engineering. Rome, Italy, 2, 2531-2540.

Yong, C., Qifu, C. and Ling, C., 1998. Vulnerability analysis in earthquake loss estimate, Earthquake Research in China, 12, 331-39.

Editorial handling: J.M. Barton Jr. 